\title{
Prevalence and risk factors associated with the comprehensive needs of cancer patients in China
}

\author{
Xin-Shuang Zhao ${ }^{1}$, Hong-Yun Wang ${ }^{1 *}$, Luo-Ling Zhang ${ }^{2}$, Yan-Hua Liư ${ }^{2}$, Hai-Yan Chen ${ }^{1}$ and Ying Wang ${ }^{3}$
}

\begin{abstract}
Background: The incidence and mortality rates of cancer have been increasing in developing countries, particularly in Asia. Therefore to provide optimal comprehensive care to the cancer patients, the care plan must focus on the comprehensive needs of cancer patients. The purpose of this study was to investigate the comprehensive needs of cancer patients, and explore the associated factors.

Methods: In a cross-sectional questionnaire study, a total of 200 cancer patient-caregiver dyads were selected and interviewed in Mainland China by convenient sampling method. Patients' comprehensive needs were assessed with Comprehensive Needs Assessment Tool in cancer for Patients (CNAT), including seven domains (Information, Psychological Problems, Health Care Staffs, Physical Symptoms, Hospital Facilities and Services, Social/Religious/ Spiritual Support and Practical Support). Both cancer patients and caregivers completed the sociodemographic survey. The mean differences in domain scores for different characteristics groups were compared by one-way ANOVA or non-parametric analyses, and influencing factors defined with multivariate regression analysis.

Results: The cancer patients' need for Health Care Staffs $(78.35 \pm 13.08)$ was the highest among the seven domains, followed by the need for Information (71.18 \pm 17.39$)$ and the need for Hospital Facilities and Services (52.65 \pm 13.35$)$.

The lowest score was the need for Physical Symptoms (35.12 \pm 16.68$)$. Patients who were female, with low family monthly income, at their own expense, and with highly educated caregivers had higher score of CNAT. Also sociodemographic characteristics were associated with each domain need of cancer patients.

Conclusion: This study shows that cancer patients experience high levels of needs for health-care staff and information, and the different needs are closely related to their sociological characteristics. The provision of health care can be adapted to meet the different needs of cancer patients of different epidemiological characteristics at different times during the course of treatment.
\end{abstract}

Keywords: Cancer, Patient, Need, Factor

\section{Background}

Recently the cancer incidence and mortality rates have been increasing in developing countries, particularly in Asia [1, 2], making cancer the leading cause of death and a major public health problem [3]. According to the latest study, the incidence rates of cancers such as lung and colorectal in some Asian countries have surpassed those of Western countries [4]. With the development of cancer

\footnotetext{
* Correspondence: zxs1214@163.com

${ }^{1}$ College of Nursing, Henan University of Science and Technology, Luoyang 471023, People's Republic of China
}

Full list of author information is available at the end of the article detection and treatment, the number of patients diagnosed with cancer is increasingly growing [5]. While a cancer diagnosis is often a sudden major event to most of patients and the family, and often sparks an abrupt need for diagnostic and treatment decisions as well as active involvement by both the patients and the family [6].

Because of the increasingly advanced treatment methods, more patients live a long period with a diagnosis of cancer, which makes cancer a big problem with continuous care [7]. As the life-threatening illness cancer is a serious challenge and a heavy stress to the patients, it would be difficult, challenging and exhausting for

(c) The Author(s). 2019 Open Access This article is distributed under the terms of the Creative Commons Attribution 4.0 International License (http://creativecommons.org/licenses/by/4.0/), which permits unrestricted use, distribution, and reproduction in any medium, provided you give appropriate credit to the original author(s) and the source, provide a link to the Creative Commons license, and indicate if changes were made. The Creative Commons Public Domain Dedication waiver (http://creativecommons.org/publicdomain/zero/1.0/) applies to the data made available in this article, unless otherwise stated. 
cancer patients to cope with sudden disease $[7,8]$. And as a result, the cancer patients suffer from the disease burden, such as physical discomfort, mental stress and economic pressure, associated with the symptoms and treatment of cancer $[9,10]$. The care activities of cancer patients include estimating, planning, decision making, symptom assessment, problem solving, and accessing health system. This complex care of cancer patients needs comprehensive knowledge and skills while many patients are uncertain about the concrete situation and severity of disease, survival time, how to improve the condition, and how to adjust the psychological pressure [11].

Patient-centred care is the gold standard for provision of healthcare in the world [12]. It need to be recognized that cancer patients have legitimate needs for help from health care professionals and the social support. Recently, the International Psycho-oncology Society (IPOS) published its Standard of Quality Cancer Care [13], a new quality standard to support the development and implementation of new clinical practice guidelines. Accordingly, care should no longer focus solely on delivery of medical treatment but also look to encompass the person's needs for information, practical support, psychological and social support in order to fully support that person's physical, emotional and psychological wellbeing throughout their illness. And if the needs of patients were not met, it may have impact on their mental and physical health, and consequently patients may miss the disease recovery.

Therefore to provide optimal comprehensive care to the cancer patients, the care plan must focus on the comprehensive needs of cancer patients [14]. In terms of symptom management and pressure adjustment, the majority of patients needed substantial help, however that need was unmet for in many previous studies $[15,16]$. These results are directly linked to the patients' quality of life, personal aspirations, values, and quality of their relations and needs. For healthcare staffs, assessment of these various needs means that they need to pay more attention to the patients themselves as individuals during the various stages of their disease, beginning from diagnosis until the terminal phase.

Although many studies have investigated the prevalence of the unmet needs among various types of cancer patients in Asian countries, only the information need, psychosocial need or some unilateral need was explored, or just one particular type of cancer, lack of comprehensiveness [17-19]. Several factors associated with high care needs had been confirmed by some previous studies, such as socio-demographic factors (age, gender, education level, marital status or financial situation), and clinical factors (sick time, severity, type of treatment received and physical function) [7, 8, 20]. Early detection of the comprehensive needs of cancer patients is important not only to reduce the suffering caused to the patient but it may improve the quality of cancer care [21].

So it is very important to understand the comprehensive needs of cancer patients for developing and improving services to address the identified gaps in cancer care [22]. The original scales were developed for cancer patients and caregivers, of which one was CNAT (for patients) and the other was CNAT-C (for caregivers). On the other hand, due to the particularity of cancer disease, patients are closely related to caregivers and interact with each other, so this study was conducted among patients but also caregivers. The aim of this study was to measure the comprehensive needs of cancer patients, and explore the possible factors associated with their needs.

\section{Methods \\ Subjects and procedure}

From April to October 2016, the cross-sectional study recruited participants involving cancer patients and caregivers from four tertiary hospitals in China by convenient sampling method: First Affiliated Hospital of Henan University of Science and Technology, Second Affiliated Hospital of Henan University of Science and Technology, Renmin Hospital of Henan Province, and Zhongxin Hospital of Luoyang. This study had been approved by the Human Research Ethics Committee of Henan Medical Association (2015-081025). Inclusion criteria for the cancer patients were: (1) over 18 years old; (2) being diagnosed with cancer; (3) currently receiving treatment or follow-up; (4) having the ability to read and write Chinese, and (5) willing to give their informed consents to participate in the study. The sample size was calculated by the following formula, $N=\left(\frac{U_{\alpha} \sigma}{\delta}\right)^{2}$. In the formula, $U_{\alpha}$ is the $U$ value corresponding to the testing level $\alpha$, and $\sigma$ is the total standard deviation, and $\delta$ is the admissible error. The total of 216 questionnaires were actually distributed and the response rate was $92.6 \%$ (200 of 216 were returned). The final number of completed cases was 200 cancer patients and 200 caregivers (See Table 1 for the basic characteristics of these participants).

In the procedure, written consent forms were signed by all participants after they fully understood the study. Anonymity and confidentiality were assured and participants were told that they could withdraw at any point without adverse consequences. Data was collected by the researchers with the unified guide language and data collecting procedure. The research team member checked the questionnaire for completion, and asked the participant to respond to each unanswered item. Patients' comprehensive needs were assessed with Comprehensive Needs Assessment Tool in cancer for Patients (CNAT), along with the socio-demographic questionnaire. 
Table 1 Demographic characteristics of 200 dyads of cancer patients and caregivers

\begin{tabular}{|c|c|}
\hline & N (\%)/Mean \pm SD \\
\hline \multicolumn{2}{|l|}{ Patient $\left(\mathrm{N}_{1}=200\right)$} \\
\hline Age & $54.87 \pm \pm 12.45$ \\
\hline$\geq 60$ & $129(64.5)$ \\
\hline$<60$ & $71(35.5)$ \\
\hline \multicolumn{2}{|l|}{ Gender } \\
\hline Male & $96(48.0)$ \\
\hline Female & $104(52.0)$ \\
\hline \multicolumn{2}{|l|}{ Ethnic } \\
\hline Han & $194(97.0)$ \\
\hline Minorities & $6(3.0)$ \\
\hline \multicolumn{2}{|l|}{ Occupation } \\
\hline No fixed occupation & $35(17.5)$ \\
\hline worker & $17(8.5)$ \\
\hline farmer & $85(42.5)$ \\
\hline Cadre & $22(11.0)$ \\
\hline retire & $35(17.5)$ \\
\hline Others & $6(3.0)$ \\
\hline \multicolumn{2}{|l|}{ Marital status } \\
\hline married & $188(94.0)$ \\
\hline unmarried & $7(3.5)$ \\
\hline widowed & $5(2.5)$ \\
\hline divorced & $0(0)$ \\
\hline \multicolumn{2}{|l|}{ Education } \\
\hline Primary school & $53(26.5)$ \\
\hline Junior high school & $71(35.5)$ \\
\hline Senior high school & $53(26.5)$ \\
\hline College & $23(11.5)$ \\
\hline \multicolumn{2}{|c|}{ Family monthly income per capita (yuan) } \\
\hline$<500$ & $50(25.0)$ \\
\hline $500 \sim 1000$ & $63(31.5)$ \\
\hline $1000 \sim 2000$ & $48(24.0)$ \\
\hline$>2000$ & 39 (19.5) \\
\hline \multicolumn{2}{|l|}{ Medical expense } \\
\hline Public expense & $11(5.5)$ \\
\hline Own expense & $20(10.0)$ \\
\hline Medical insurance & $169(84.5)$ \\
\hline \multicolumn{2}{|l|}{ Metastasis } \\
\hline No & $95(47.5)$ \\
\hline Yes & $105(52.5)$ \\
\hline \multicolumn{2}{|l|}{ Type of disease } \\
\hline Digestive system & $90(45.0)$ \\
\hline Respiratory system & $34(17.0)$ \\
\hline Blood system & $4(2.0)$ \\
\hline
\end{tabular}

Table 1 Demographic characteristics of 200 dyads of cancer patients and caregivers (Continued)

\begin{tabular}{|c|c|}
\hline & N (\%)/Mean \pm SD \\
\hline Reproductive system & $8(4.0)$ \\
\hline Osteosarcoma & $14(7.0)$ \\
\hline Others & $50(25.0)$ \\
\hline \multicolumn{2}{|l|}{ Time since diagnosis (year) } \\
\hline$<1$ & $143(71.5)$ \\
\hline $1 \sim 3$ & $36(18.0)$ \\
\hline$>3$ & $21(10.5)$ \\
\hline \multicolumn{2}{|l|}{ Treatment measures } \\
\hline operation & $30(15.0)$ \\
\hline radiotherapy & $10(5.0)$ \\
\hline chemotherapy & $41(20.5)$ \\
\hline comprehensive therapy & $119(59.5)$ \\
\hline \multicolumn{2}{|l|}{ Caregiver $\left(\mathrm{N}_{2}=200\right)$} \\
\hline Age & $44.26 \pm 11.51$ \\
\hline$\geq 60$ & $57(28.5)$ \\
\hline$<60$ & $143(71.5)$ \\
\hline \multicolumn{2}{|l|}{ Gender } \\
\hline Male & $98(49.0)$ \\
\hline Female & $102(51.0)$ \\
\hline \multicolumn{2}{|l|}{ Ethnic } \\
\hline Han & $198(99.0)$ \\
\hline Minorities & $2(1.0)$ \\
\hline \multicolumn{2}{|l|}{ Occupation } \\
\hline No fixed & $45(22.5)$ \\
\hline occupation & $31(15.5)$ \\
\hline worker & $63(31.5)$ \\
\hline farmer & $29(14.5)$ \\
\hline Cadre & $19(9.5)$ \\
\hline retire others & $13(6.5)$ \\
\hline \multicolumn{2}{|l|}{ Marital status } \\
\hline married & $167(83.5)$ \\
\hline unmarried & $30(15.0)$ \\
\hline widowed & $2(1.0)$ \\
\hline divorced & $1(0.5)$ \\
\hline \multicolumn{2}{|l|}{ Education } \\
\hline Primary school & $22(11.0)$ \\
\hline Junior high school & $65(32.5)$ \\
\hline Senior high school & $54(27.0)$ \\
\hline College & $59(29.5)$ \\
\hline \multicolumn{2}{|c|}{ Family monthly income per capita (yuan) } \\
\hline$<500$ & $32(16.0)$ \\
\hline $500 \sim 1000$ & $60(30.0)$ \\
\hline $1000 \sim 2000$ & $53(26.5)$ \\
\hline
\end{tabular}


Table 1 Demographic characteristics of 200 dyads of cancer patients and caregivers (Continued)

\begin{tabular}{ll}
\hline & $\mathrm{N}(\%) /$ Mean \pm SD \\
Number of caregivers & $55(27.5)$ \\
1 & \\
2 & $119(59.5)$ \\
3 or more & $63(31.5)$ \\
Together with patient & $18(9.0)$ \\
Yes & \\
No & $181(90.5)$ \\
Relationship with patient & $19(9.5)$ \\
Spouse & \\
Brother /sister & $84(42.0)$ \\
Child & $3(1.5)$ \\
Parent & $88(44.0)$ \\
others & $18(9.0)$ \\
\hline
\end{tabular}

\section{Measures \\ CNAT}

The CNAT was initially developed and validated by Shim E.J. in a large scale involving 2661 cancer patients throughout Korea [23]. The Cronbach's $\alpha$ for the scale was 0.97 , and for subscales, it varied from 0.80 to 0.97 . Principal component analysis resulted in an 7-factor structure explaining $64.2 \%$ of the total variance. For the first time, CNAT was translated into Chinese to assess the comprehensive needs of cancer patients in China. The Chinese version of CNAT has 59 items, a total of seven domains(Information, Psychological Problems, Health Care Staffs, Physical Symptoms, Hospital Facilities and Services, Social /Religious /Spiritual Support and Practical Support), assessing the comprehensive needs of cancer patients. Each item is scored from 0 to 3 . " 0 " indicates "no need", " 1 " indicates "low need", "2" indicates "moderate need", while " 3 " indicates "high need". Standardization scoring method: Each dimension score $=$ the practical score ${ }^{*} 100 /$ items $^{*} 3$ [24]. The Cronbach's $\alpha$ coefficient for the total CNAT score was 0.952, and 0.824-0.948 for the eight domains. Principal component analysis resulted in an 8-factor structure explaining $70.325 \%$ of the total variance [25].

\section{Cancer patients general information questionnaire}

This questionnaire contains 12 items, regarding sociodemographic and medical variables, such as age, gender, nationality, occupation, marital status, educational level, financial situation, with or without medical insurance, metastasis, disease type, time since diagnosis, and type of treatment.

\section{Caregiver general information questionnaire}

This questionnaire contains 15 items, regarding sociodemographic and medical variables, such as age, gender, nationality, occupation, marital status, educational level, financial situation, number of caregivers, whether to live with patients, relationship with patients. Diagnosis and disease stage were both retrieved from hospital information systems at the participating centers. Diagnosis of the cancer was divided into digestive system cancer/ breast cancer/ respiratory system cancer/osteosarcoma/ reproductive system or other types. Disease stage of the patient was divided into two types "cancer metastasis or no cancer metastasis".

\section{Statistical analyses}

All statistical analyses were performed with SPSS for Windows statistical software, version 20.0 s (IBM Corp., Armonk, NY, USA). All tests were bilateral, and $p<0.05$ was considered as statistically significant.

The statistical description of the socio-demographic variables was carried out by frequency tables, means, and standard deviations. Domain scores of the comprehensive needs were calculated by averaging the score for each domain with subsequent linear transformation to a scale of $0-100$ based on the EORTC scoring guideline [24]. For patients group, the mean differences in domain scores for different characteristics groups were compared by either one-way ANOVA or non-parametric analyses to see how these scores related to their sociodemographic and patients' clinical characteristics (such as, the degree of disease, the treatment type and duration of cancer), depending on whether the data were normally or not normally distributed [26]. In this preliminary analysis, the total and each of the seven domains of the CNAT score were entered as dependent variables. The independent variables included age, gender, nationality, occupation, marital status, educational level, financial situation, with or without medical insurance, metastasis, disease type, time since diagnosis, and type of treatment. Second, multivariate regression analysis was performed to evaluate the related factors of the comprehensive needs and each domain need.

\section{Results}

\section{Participant characteristics}

The socio-demographic characteristics of cancer patients and caregivers were listed in Table 1 . The mean age of cancer patients was 54.87 years old $(\mathrm{SD}=12.45)$, and $52.0 \%$ were female. Most of the patients $(84.5 \%)$ had the medical insurance. $52.5 \%$ had metastasis, and the treatment measures varied. Regarding the duration of cancer since diagnosis, $71.5 \%$ was less than 1 year. The main cancer types are digestive system $(45.0 \%)$, breast cancer (25.0\%), and respiratory system (17.0\%). 


\section{The comprehensive needs of cancer patients}

Overall, the comprehensive needs of cancer patients was moderate, with the standardized total score 51.25 ( $\mathrm{SD}=$ 9.69). The mean scores of each domain were listed in the Table 2. The highest score of need was for Health Care Staffs $(78.35 \pm 13.08)$, followed by Information (71.18 \pm 17.39$)$ and Hospital Facilities and Services $(52.65 \pm 13.35)$. Conversely, the lowest need was for Physical Symptoms (35.12 \pm 16.68$)$.

\section{Factors associated with the comprehensive needs of cancer patients}

In the Table 3, significant differences were found in the comprehensive needs of cancer patients according to the various patients and caregivers characteristics. In this preliminary analysis, patients who were younger, female, with low family monthly income, at their own expense, more than 3 years after diagnosis, and with highly educated caregivers had higher score of CNAT. Then, in multivariate regression analysis, the nominal scale variable was converted to dummy variables. As a result, the factor with the greatest influence on the comprehensive needs(total score of CNAT) of cancer patients was "gender (female)", followed by "medical insurance (at their own expense)" (Table 4). The overview of the risk factors of the comprehensive needs and each domain need of cancer patients was presented in Table 4. For the first domain(Information), the gender, medical insurance, education and the number of caregivers were significantly associated with this need. In the domain of Psychological Problems, the gender, medical insurance, income, and with or no metastases were related to this need. For Health-care staff, the gender, medical insurance and education showed a higher need. The age, gender and treatment measures were related to the need for Physical Symptoms. For the domain of Hospital Facilities and Services, income, treatment measures, the age of caregivers, showed a higher need. The gender, education, and with or no metastasis showed a higher need for Social and Religious / Spiritual Support. The gender, medical insurance, income, duration of disease, the age of caregivers, showed a higher need for Practical Support.

\section{Discussion}

The present study is a questionnaire study including a relatively large sample of cancer patients with a range of cancer diagnoses at different times using the newly developed and validated questionnaire CNAT by specifically investigating the prevalence and risk factors of the comprehensive needs of cancer patients. Most previous studies addressing cancer patients have focused on the unmet needs $[7,11,12,16,27-29]$ or a single kind of demand (such as supportive care demand [7, 8, 14, 15] and information need [17, 30,31] or solely one kind of cancer(such as breast cancer, haematological cancer, lung cancer, Head and Neck Cancer, or cervical cancer). In addition, no previous studies have investigated the comprehensive needs of cancer patients (covering almost all aspects of demand) and their influencing factors. Therefore this study is a valuable supplement to the existing studies of cancer care. Moreover examining the comprehensive needs of cancer patients can inform the tailoring of interventions or supports to the specific needs, in order to enhance their quality of life [32].

Regarding the cancer patients' status of need, one finding in this study was that the overall need of cancer patients was at medium upper level in agreement with previous findings $[8,33]$. Among the seven domains of needs, the highest score was the need for Health Care Staffs, followed by the need for Information and the need for Hospital Facilities and Services, which was to some extent in accordance with the preview studies including the unmet needs for health system, information, and patient support $[34,35]$. Most patients have always wanted a hospital staff who can talk about all aspects of their condition, treatment, and follow-up, with remaining unmet needs addressing mostly desire for information [36]. Our finding that the lowest score was the need for Physical Symptoms domain (35.12 \pm 16.68$)$, was inconsistent with a systematic review [37], which found the most frequently reported unmet needs were those in the activities of daily living domain, followed by psychological, information, psychosocial and physical domain, suggesting that the Chinese cancer patients were more inclined to focus on the needs of other aspects than the physical symptoms.

Table 2 The Comprehensive needs of cancer patients

\begin{tabular}{lllllllll}
\hline & Information & $\begin{array}{l}\text { Psychological } \\
\text { Problems }\end{array}$ & $\begin{array}{l}\text { Health Care } \\
\text { Staffs }\end{array}$ & $\begin{array}{l}\text { Physical } \\
\text { Symptoms }\end{array}$ & $\begin{array}{l}\text { Hospital Facilities } \\
\text { and Services }\end{array}$ & $\begin{array}{l}\text { Social /Religious / } \\
\text { Spiritual Support }\end{array}$ & $\begin{array}{l}\text { Practical } \\
\text { Support }\end{array}$ & $\begin{array}{l}\text { Standardized } \\
\text { total score }\end{array}$ \\
\hline N $\quad$ Valid & 200 & 200 & 200 & 200 & 200 & 200 & 0 & 200 \\
Missing & 0 & 0 & 0 & 0 & 0 & 0 & 0 & 0 \\
Mean value & 71.1833 & 51.8333 & 78.3542 & 35.1250 & 52.6458 & 38.3000 & 39.0278 & 51.2514 \\
SD & 17.39153 & 11.86331 & 13.08062 & 16.68756 & 13.34700 & 12.46156 & 15.25653 & 9.69639 \\
Minimum & 0.00 & 0.00 & 4.17 & 0.00 & 0.00 & 0.00 & 0.00 & 1.69 \\
Maximum & 100.00 & 100.00 & 100.00 & 100.00 & 100.00 & 100.00 & 100.00 & 93.22 \\
\hline
\end{tabular}




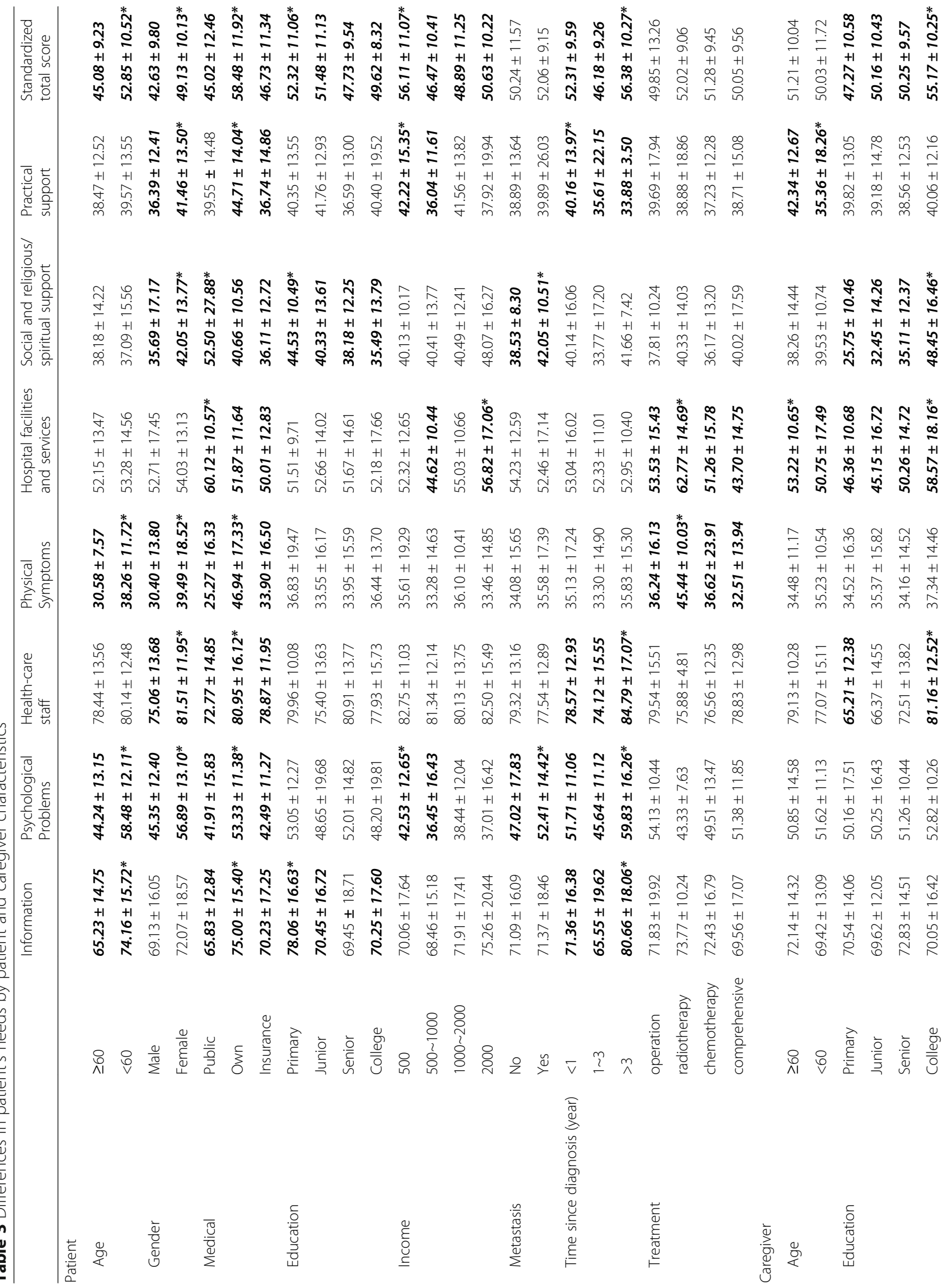




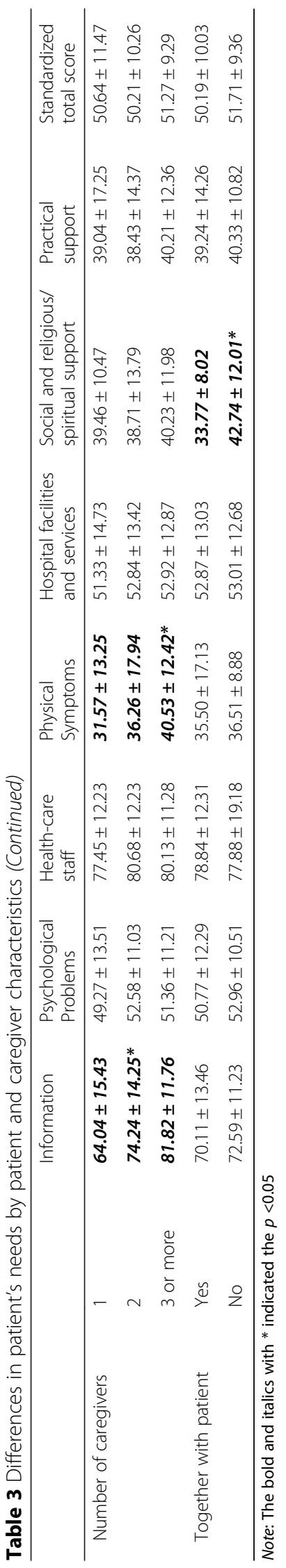


Table 4 Regression analysis for the comprehensive needs and each domain need and influencing factors

\begin{tabular}{|c|c|c|c|c|}
\hline Dependent variable & Independent variable ${ }^{a}$ & $\beta$ & SE & $p$ \\
\hline \multirow[t]{4}{*}{ Standardized total score of CNAT } & Gender (Female) & 0.423 & 4.308 & $<0.001$ \\
\hline & Medical insurance (at their own expense) & 0.327 & 3.257 & $<0.001$ \\
\hline & Income (500) & 0.236 & 4.336 & 0.015 \\
\hline & Caregiver Education (college) & 0.303 & 2.205 & $<0.001$ \\
\hline \multirow[t]{4}{*}{ Information } & Age (Younger: <60) & 0.201 & 3.535 & 0.003 \\
\hline & Medical insurance (at their own expense) & 0.423 & 4.367 & $<0.001$ \\
\hline & Education (Primary) & 0.218 & 3.264 & 0.021 \\
\hline & Number of caregivers(3 or more) & 0.406 & 1.039 & $<0.001$ \\
\hline \multirow[t]{4}{*}{ Psychological Problems } & Gender (Female) & 0.228 & 2.541 & $<0.001$ \\
\hline & Medical insurance (at their own expense) & 0.103 & 1.346 & 0.006 \\
\hline & Income (500) & 0.207 & 4.208 & $<0.001$ \\
\hline & Metastasis (YES) & 0.114 & 2.335 & 0.034 \\
\hline \multirow[t]{3}{*}{ Health-care staff } & Gender (Female) & 0.218 & 4.039 & 0.007 \\
\hline & Medical insurance (at their own expense) & 0.135 & 2.357 & 0.018 \\
\hline & Caregiver Education (college) & 0.323 & 1.268 & $<0.001$ \\
\hline \multirow[t]{3}{*}{ Physical Symptoms } & Age (Younger: <60) & 0.236 & 2.553 & $<0.001$ \\
\hline & Gender (Female) & 0.307 & 3.542 & $<0.001$ \\
\hline & Treatment (radiotherapy) & 0.229 & 2.367 & 0.004 \\
\hline \multirow[t]{3}{*}{ Hospital Facilities and Services } & Income (2000) & 0.359 & 2.158 & $<0.001$ \\
\hline & Treatment (radiotherapy) & 0.225 & 3.346 & 0.011 \\
\hline & Caregiver age $(\geq 60)$ & 0.310 & 2.107 & $<0.001$ \\
\hline \multirow[t]{3}{*}{ Social and Religious / Spiritual Support } & Gender (Female) & 0.327 & 2.038 & 0.001 \\
\hline & Income (500) & 0.129 & 2.104 & 0.023 \\
\hline & Metastasis (YES) & 0.402 & 3.238 & $<0.001$ \\
\hline \multirow[t]{5}{*}{ Practical Support } & Gender (Female) & 0.405 & 3.208 & $<0.001$ \\
\hline & Medical insurance (at their own expense) & 0.346 & 2.117 & 0.001 \\
\hline & Income (500) & 0.228 & 1.259 & $<0.001$ \\
\hline & Time since diagnosis ( $<1$ year $)$ & 0.309 & 2.037 & $<0.001$ \\
\hline & Caregiver age $(\geq 60)$ & 0.254 & 2.368 & 0.037 \\
\hline
\end{tabular}

${ }^{a}$ Dummy variables: Gender (male) $=0$, Age $(\geq 60)=0$, Medical insurance (public) $=0$, Income $(500 \sim 1000)=0$, Education (college) $=0$, Metastasis (NO) $=0$, Time since diagnosis $(1 \sim 3$ year $)=0$, Treatment (comprehensive $)=0$, Caregiver age $(<60)=0$, Caregiver Education $($ Primary $)=0$

Our study also indicates that subgroups of cancer patients experience different types of needs, with the predictors of reporting some unmet need for help varying according to the domain examined. Sociodemographic characteristics were associated with comprehensive needs of cancer patients. In general, comprehensive care should be given to these patients who were female, with low family monthly income, at their own expense and with highly educated caregivers.

The present study indicated that gender is a relevant factor for being at risk of having more comprehensive needs and that female cancer patients are more likely to have unmet needs than male patients, especially need for Psychological Problems [38]. Similar findings have been confirmed to explain this difference, such as the female gender being associated with increased anxiety and/or depressive disorders [39]. Due to gender factor, female cancer patients are more psychologically affected than male patients and think more about many aspects of the disease [40], which in turn leads to higher demand, especially for Psychological Problems [34], Health-care staff, Physical Symptoms, Social and religious / spiritual support and Practical Support. Therefore, female cancer patients should be monitored more carefully and may be a target population for providing more intensive care.

Owing to the high cost of treatment, low-income patients with cancer experienced high levels of unmet needs across a wide range of psychosocial needs, such as the practical, health professional and cancer-related information, which had been confirmed by previous studies [41]. Likewise, 
many patients at their own expense also face economic pressure because of no insurance, which may lead to high need for psychosocial support, especially financial support. Financial stress and strain due to cancer, have been shown to be associated with adverse psychological outcomes in breast and prostate cancer patients $[42,43]$ and thus the intersection with psychological unmet needs is not unexpected. Accordingly, to bridge the gap between increasing cancer patients needs and limited resources, the development of interventions designed to aid in cancer patients screening and resource identification should be suggested.

Our data may suggest that patients with lower educational levels or with highly educated caregivers reported higher comprehensive needs. These findings correspond with the results of the previous studies [44, 45]. It may be that cancer patients with lower educational levels reported a greater need for transportation services, treatment near their house and help with economic burden, as well as help with worries that they would become a burden to others. On the other hand, the educated caregivers have better access to health facilities and information about cancer care, whereas they need more information about how to provide better care of the patients.

Analysis of influencing factors of needs in different domains indicated special consideration may need to be given when planning the care of cancer patients of different characteristics; such as focusing on providing information for younger, at their own expense, less educated patients and with three or more caregivers. For patients who were female, at their own expense, low income and with metastasis, necessary psychological care may need to be provided. And for female patients who were at their own expense and with highly educated caregivers, health-care staffs should communicate more with them to increase their sense of trust and security. Younger, female patients and perceived with radiotherapy showed a greater need for physical symptoms, so more interpretation and guidance should be provided to them. For patients with high income, perceived with radiotherapy, with older caregivers, the provision hospital facilities and services should be paid more attention to. Social and religious / spiritual support should be provided for female patients, low educated and with metastasis. Last, practical support should be provided for female patients, with medical care at their own expense, low income, diagnosed less than a year and with older caregivers, such as transportation services or financial support. These findings suggest that interventions that mobilize social and health care support may, therefore, provide multilevel benefits across the cancer trajectory according to the different characteristics of patients [38].

\section{Limitation}

Even though the present study provides important information of comprehensive needs of cancer patients, it has some limitations including the cross-sectional design, sample bias, and the small sample size. First, participants in the study were drawn mainly from hospital patients who were receiving or had received treatment for their disease. This selection bias may have implications for the findings of the study to some extent. The findings therefore are likely to relate to the experiences of a sub-group of individuals who may be fitter than those who receive hospital treatment alone. Second, there is a risk of bias across the study to detect potentially vulnerable subgroups as being at risk because these subgroups are too small in numbers to be quantitatively analyzed as potential predictors of need. While the present study is able to elicit specific needs, it has small biased sample and we cannot generalize these findings to all cancer survivors. Further studies should be undertaken to confirm the present findings.

\section{Conclusions}

In view of our findings, we conclude that cancer patients experience high levels of needs for health-care staff and information, and the different needs are closely related to their sociological characteristics. Understanding the comprehensive needs of patients with cancer is essential to improving the care and outcomes. These findings highlight the importance of providing adequate support to address the diversity of patients needs, thereby ensuring sustainable provision of care and support to the patients. Future studies should incorporate patients' care interventions to better understand those individual situations and how they may influence the outcomes of cancer patients.

\section{Abbreviation}

CNAT: Comprehensive Needs Assessment Tool in cancer for Patients

\section{Acknowledgements}

We gratefully acknowledge the support of the several hospitals in Henan Povince. As well, we would like to thank the advisory committee, coinvestigators, research assistants, and all patients for participating in the study.

\section{Authors' contributions \\ ZHAO XS: study design, data collection, manuscript preparation; WANG HY: study design, manuscript review; ZHANG LL: study design, manuscript review; LIU YH: data collection, manuscript preparation; CHEN HY: data collection; WANG Y: data} collection; All authors read and approved the final version of manuscript.

\section{Funding}

This research was funded by Henan Science and Technology Department Project (172102310507)

\section{Availability of data and materials}

The data used for this study is confidential and cannot be made public. Individuals interested in obtaining specific data may contact Dr. Hongyun WANG (zxs1214@163.com).

Ethics approval and consent to participate

All procedures performed in studies involving human participants were in accordance with the ethical standards of the institutional and/or national research committee and with the 1964 Helsinki declaration and its later amendments or comparable ethical standards. 


\section{Consent for publication}

Written, informed consent was obtained from all individual participants and/ or their legal guardians included in the study.

\section{Competing interests}

The authors declare that they have no competing interests.

\section{Author details}

${ }^{1}$ College of Nursing, Henan University of Science and Technology, Luoyang 471023, People's Republic of China. ${ }^{2}$ The 1st Affiliated Hospital of Henan University of Science and Technology, Luoyang 471023, People's Republic of China. ${ }^{3}$ Henan University of Science and Technology, Luoyang 471023, People's Republic of China.

\section{Received: 11 April 2018 Accepted: 3 June 2019}

Published online: 13 June 2019

\section{References}

1. Torre LA, Bray F, Siegel RL, Ferlay J, Lortet-Tieulent J, Jemal A. Global cancer statistics, 2012. CA Cancer J Clin. 2015;65(2):87-108.

2. Pourhoseingholi MA, Ashtari S, Hajizadeh N, Fazeli Z, Zali MR. Systematic review of pancreatic cancer epidemiology in Asia-Pacific region: major patterns in GLOBACON 2012. Gastroenterol Hepatol Bed Bench. 2017;10(4):245-57.

3. Chen W, Zheng $R$, Baade PD, Zhang S, Zeng H, Bray F, Jemal A, Yu XQ, He J. Cancer statistics in China, 2015. CA Cancer J Clin. 2016:66(2):115-32.

4. Chirk JN, Chin HT, Nurdiana A, et al. Relationships between cancer pattern, country income and geographical region in Asia. BMC Cancer. 2015;15:613.

5. Matsuda T, Saika K. Worldwide burden of Cancer incidence in 2002 extrapolated from Cancer incidence in five continents Vol. IX. Jpn J Clin Oncol. 2012:42(11):1111-2

6. Cui J, Song $\sqcup$, Zhou $\sqcup$, et al. Needs of family caregivers of advanced cancer patients: a survey in Shanghai of China. Eur J Cancer Care (Engl). 2014;23(4):562-9.

7. Ullrich A, Ascherfeld L, Marx G, Bokemeyer C, Bergelt C, Oechsle K. Quality of life, psychological burden, needs, and satisfaction during specialized inpatient palliative care in family caregivers of advanced cancer patients. BMC Palliat Care. 2017:16(1):31.

8. Uchida M, Akechi T, Okuyama T, et al. Patients' supportive care needs and psychological distress in advanced breast cancer patients in Japan. Jpn J Clin Oncol. 2011;41(4):530-6.

9. Schmitz KH, Speck RM. Risks and benefits of physical activity among breast cancer survivors who have completed treatment. Womens Health (Lond). 2010;6(2):221-38

10. Berian JR, Cuddy A, Francescatti AB, O'Dwyer L, Nancy You Y, Volk RJ, Chang GJ. A systematic review of patient perspectives on surveillance after colorectal cancer treatment. J Cancer Surviv. 2017:11(5):542-52.

11. Chiesi F, Bonacchi A, Primi C, Miccinesi G. Assessing unmet needs in patients with cancer: an investigation of differential item functioning of the needs evaluation questionnaire across gender, age and phase of the disease. PLoS One. 2017:12(7):e0179765.

12. Swash B, Hulbert-Williams N, Bramwell R. Unmet psychosocial needs in haematological cancer: a systematic review. Support Care Cancer. 2014. 22(4):1131-41.

13. Holland J, Watson M, Dunn J. The IPOS new international standard of quality Cancer care: integrating the psychosocial domain into routine care. Psycho-Oncology. 2011;20(7):677-80.

14. Maguire R, Papadopoulou C, Kotronoulas G, et al. A systematic review of supportive care needs of people living with lung cancer. Eur J Oncol Nurs. 2013;17(4):449-64.

15. Lam WW, Au AH, Wong JH, et al. Unmet supportive care needs: a crosscultural comparison between Hong Kong Chinese and German Caucasian women with breast cancer. Breast Cancer Res Treat. 2011;130(2):531-41.

16. Morrison V, Henderson BJ, Zinovieff F, et al. Common, important, and unmet needs of cancer outpatients. Eur J Oncol Nurs. 2012;16(2):115-23.

17. Fang CY, Heckman CJ. Informational and support needs of patients with head and neck Cancer: current status and emerging issues. Cancers Head Neck. 2016;1(15). https://doi.org/10.1186/s41199-016-0017-6.

18. Cardoso F, Harbeck N, Mertz S, et al. Evolving psychosocial, emotional, functional, and support needs of women with advanced breast cancer: results from the count us, know us, join us and Here \& now surveys. Breast. 2016;28:5-12.
19. Sharma RK, Astrow AB, Texeira K, et al. The spiritual needs assessment for patients (SNAP): development and validation of a comprehensive instrument to assess unmet spiritual needs. J Pain Symptom Manag. 2012; 44(1):44-51.

20. Zebrack BJ, Block R, Hayes-Lattin B, et al. Psychosocial service use and unmet need among recently diagnosed adolescent and young adult cancer patients. Cancer. 2013;119(1):201-14.

21. Luutonen $\mathrm{S}$, Vahlberg $\mathrm{T}$, Eloranta $\mathrm{S}$, et al. Breast cancer patients receiving postoperative radiotherapy: distress, depressive symptoms and unmet needs of psychosocial support. Radiother Oncol. 2011;100(2):299-303.

22. White K, D'Abrew N, Katris P. Et.al. Mapping the psychosocial and practical support needs of cancer patients in Western Australia. Eur J Cancer Care (Engl). 2012:21(1):107-16.

23. Shim EJ, Lee KS, Park JH, et al. Comprehensive needs assessment tool in cancer (CNAT): the development and validation. Support Care Cancer. 2011; 19(12):1957-68.

24. Shin DW, Park JH, Shim EJ, et al. The development of a comprehensive needs assessment tool for cancer-caregivers in patient-caregiver dyads. Psychooncology. 2011;20(12):1342-52.

25. XS Z, LL Z, LI ZZ. Validation of Chinese version of the comprehensive needs assessment tool for cancer patients. Chin J Nurs. 2017:52(1):34-9 In Chinese.

26. Awadalla AW, Ohaeri JU, Gholoum A, et al. Factors associated with quality of life of outpatients with breast cancer and gynecologic cancers and their family caregivers: a controlled study. BMC Cancer. 2007;7:102

27. Scagliotti GV, Bironzo P, Vansteenkiste JF. Addressing the unmet need in lung cancer: the potential of immune-oncology. Cancer Treat Rev. 2015;41(6):465-75.

28. Walling $\mathrm{AM}$, Keating $\mathrm{NL}$, Kahn $\mathrm{KL}$, et al. Lower patient ratings of physician communication are associated with unmet need for symptom Management in Patients with Lung and Colorectal Cancer. J Oncol Pract. 2016;12(6):e654-69.

29. King AJ, Evans M, Moore TH, et al. Prostate cancer and supportive care: a systematic review and qualitative synthesis of men's experiences and unmet needs. Eur J Cancer Care (Engl). 2015;24(5):618-34.

30. Alamanou GD, Balokas AS, Fotos VN, et al. Information needs of cancer patients: validation of the Greek Cassileth's information styles questionnaire. Eur J Oncol Nurs. 2016;20:49-57.

31. Beernaert K, Haverbeke C, Van Belle S, et al. Information needs about palliative care and euthanasia: a survey of patients in different phases of their cancer trajectory. Patient Educ Couns. 2018;101(1):132-8.

32. So WK, Choi KC, Chen JM, et al. Quality of life in head and neck cancer survivors at 1 year after treatment: the mediating role of unmet supportive care needs. Support Care Cancer. 2014;22(11):2917-26.

33. Bibby $\mathrm{H}$, White $\mathrm{V}$, Thompson $\mathrm{K}$, et al. What are the unmet needs and care experiences of adolescents and Young adults with Cancer? A systematic review. J Adolesc Young Adult Oncol. 2017;6(1):6-30.

34. Sakamoto N, Takiguchi S, Komatsu H, et al. Supportive care needs and psychological distress and/or quality of life in ambulatory advanced colorectal cancer patients receiving chemotherapy: a cross-sectional study. Jpn J Clin Oncol. 2017;47(12):1157-61

35. Nguyen T, Anota A, Brédart A, et al. A longitudinal analysis of patient satisfaction with care and quality of life in ambulatory oncology based on the OUT-PATSAT35 questionnaire. BMC Cancer. 2014:14(1):1-12.

36. Au A, Lam W, Tsang J, et al. Supportive care needs in Hong Kong Chinese women confronting advanced breast cancer. Psychooncology. 2013:22(5):1144-51.

37. Harrison JD, Young JM, Price MA, et al. What are the unmet supportive care needs of people with cancer? A systematic review. Support Care Cancer. 2009; 17(8):1117-28

38. Rowlands IJ, Janda M, McKinnon L, et al. Prevalence, predictors, and correlates of supportive care needs among women 3-5 years after a diagnosis of endometrial cancer. Support Care Cancer. 2014;23:1205-14.

39. Bijl RV, De Graaf R, Ravelli A, et al. Gender and age-specific first incidence of DSMIII-R psychiatric disorders in the general population. Results from the Netherlands mental health survey and incidence study (NEMESIS). Soc Psychiatry Psychiatr Epidemiol. 2002;37:372-9.

40. Urbaniec OA, Collins K, Denson LA, et al. Gynecological cancer survivors: assessment of psychological distress and unmet supportive care needs. J Psychosoc Oncol. 2011:29:534-51.

41. Yi M, Park K, Park EY. Psychosocial needs of low-income people with cancer in Korea. Eur J Oncol Nurs. 2014:18(6):549-56.

42. Sharp L, Carsin A-E, Timmons A. Associations between cancer-related financial stress and strain and psychological well-being among individuals living with cancer. Psycho-Oncology. 2013;22(4):745-55. 
43. Sharp L, Timmons A. Pre-diagnosis employment status and financial circumstances predict cancer-related financial stress and strain among breast and prostate cancer survivors. Support Care Cancer Off J Multinatl Assoc Support Care Cancer. 2016;24(2):699-709.

44. Matsuyama RK, Kuhn LA, Molisani A, et al. Cancer patients' information needs the first nine months after diagnosis. Patient Educ Couns. 2013;90(1):96-102.

45. Matsuyama RK, Wilson-Genderson M, Kuhn L, et al. Education level, not health literacy, associated with information needs for patients with cancer. Patient Educ Couns. 2011;85(3):e229-36.

\section{Publisher's Note}

Springer Nature remains neutral with regard to jurisdictional claims in published maps and institutional affiliations.

Ready to submit your research? Choose BMC and benefit from:

- fast, convenient online submission

- thorough peer review by experienced researchers in your field

- rapid publication on acceptance

- support for research data, including large and complex data types

- gold Open Access which fosters wider collaboration and increased citations

- maximum visibility for your research: over $100 \mathrm{M}$ website views per year

At $\mathrm{BMC}$, research is always in progress.

Learn more biomedcentral.com/submissions 